\title{
A Movimentação das Matrículas no Ensino Fundamental no Estado do Piauí
}

\author{
Luís Carlos Sales \\ Magna Jovita Gomes de Sales e Silva' \\ 'Universidade Federal do Piauí (UFPI), Teresina/PI - Brasil
}

RESUMO - A Movimentação das Matrículas no Ensino Fundamental no Estado do Piauí1 . Este artigo analisa as matrículas do Ensino Fundamental, no Estado do Piauí, das redes estadual e municipal, no período entre 1997 e 2010. Tomou-se como ponto de partida o novo financiamento da educação pública no Brasil, desenhado após a instituição do FUNDEF. Os dados foram coletados a partir de conteúdo disponibilizados no site do INEP e de informações complementares nos microdados. Ficou evidenciado que o processo de municipalização das matrículas do Ensino Fundamental, no Piauí, ocorreu mais intensamente de 1997 até 2005. As razões das peculiaridades das matrículas do Ensino Fundamental no Piauí e os contextos econômicos e políticos constituem-se objeto de futuras pesquisas.

Palavras-chave: Matrículas. Ensino Fundamental. Municipalização.

ABSTRACT - The Changes in Enrollment in Piauí's Elementary and Middle Schools. In this article are analyzed the enrolment of basic school, in the Piauí state, in the state and municipal network, in the period 1997 to 2010. It's based in the new financing of public education at Brazil, happened after the institution of FUNDEF. The data was collected from the contents available at INEP's website and additional information in the microdata. It's evidenced that the process of municipalization of the enrolment of basic school at Piauí, happened more intensive in the period of 1997 until 2005. The reasons of peculiar enrolment of basic school at Piauí and the economic and political context are the object of future research.

Keywords: Enrolment. Basic School. Municipalization.

Educação \& Realidade, Porto Alegre, v. 38, n. 4, p. 1283-1301, out./dez. 2013.1283

Disponível em: <http://www.ufrgs.br/edu_realidade> 
A Movimentação das Matrículas no Ensino Fundamental no Estado do Piauí

\section{Introdução}

Este artigo tem como objetivo analisar as matrículas do Ensino Fundamental, no Estado do Piauí, das redes estadual e municipal ${ }^{2}$, no período entre 1997 e 2010. O recorte temporal considerado levou em conta que, nesse período, vigorou o $\mathrm{FUNDEF}^{3}$ e a partir de 2007 passou a vigorar o $\mathrm{FUNDEB}^{4}$ (), fundos que alteraram a lógica de financiamento da educação nos estados, municípios e no Distrito Federal, uma vez que cada aluno matriculado passou a representar mais dinheiro para os referidos entes federados.

A participação da rede municipal de ensino nas matrículas do Ensino Fundamental na rede pública brasileira é histórica, no entanto, a partir da implantação da política de fundos, constituiu-se um elemento forte de indução à municipalização dessa etapa da Educação Básica no Brasil (Guimarães; Pinto, 2001; Callegari, 2011; Militão, 2011; Arelaro, 2007). A literatura consultada aponta mudanças no perfil da distribuição de responsabilidades entre estado e municípios no atendimento do Ensino Fundamental, a partir de 1996. Essas mudanças têm atingido, de forma indiscriminada, todo o País e acentuaram-se com a implantação do FUNDEF e mais recentemente com a do FUNDEB.

O FUNDEF era um fundo de natureza contábil que utilizava receitas provenientes de impostos e transferências, no âmbito de cada estado, caracterizando-se como um fundo estadual. A redistribuição das receitas do FUNDEF ocorria entre o estado e seus municípios, de forma proporcional à quantidade de matrículas, entre as duas redes públicas de ensino (municipal e estadual). $\mathrm{O}$ fator quantidade de matrículas estimulava essas duas redes a aumentarem suas ofertas. No Piauí, era comum, nos primeiros anos do FUNDEF, as redes de ensino público responsáveis pela oferta do Ensino Fundamental veicularem propagandas com o objetivo de atrair novos alunos. Essa situação se configurou como uma disputa por alunos, envolvendo as redes municipais e estaduais.

A transferência de matrícula no Ensino Fundamental entre as duas redes públicas de ensino (estadual e municipal) ocorreu de forma diferente nos estados brasileiros e variou conforme o contexto das redes envolvidas. Em alguns estados, a transferência de matrícula para as redes municipais ocorreu de forma mais acentuada nos anos iniciais do Ensino Fundamental, e em menor escala, nos anos finais dessa etapa do ensino. A cessão de alunos da rede estadual para a municipal ficou conhecida, na literatura, por municipalização do ensino.

$\mathrm{Na}$ ausência de estudo que analisa a movimentação das matrículas do Ensino Fundamental no Estado do Piauí, justifica-se a realização desta pesquisa, a qual visa preencher essa lacuna e conhecer a especificidade do fenômeno da municipalização em um dos estados da Região Nordeste que apresenta um dos menores valores per capita dos recursos do FUNDEB.

1284 Educação \& Realidade, Porto Alegre, v. 38, n. 4, p. 1283-1301, out./dez. 2013 Disponível em: <http://www.ufrgs.br/edu_realidade> 


\section{Municipalização, Processo e Contexto}

Os autores que discutem o tema municipalização assumem posições distintas: há os que defendem e há os que assumem posições críticas. Para os primeiros, a municipalização é um processo positivo, uma vez que possibilita melhor atendimento educacional, tendo em vista que os municípios são as instâncias mais próximas daqueles que demandam os serviços públicos. O princípio da descentralização foi uma ideia defendida no Manifesto dos Pioneiros da Educação Nova, documento redigido por Fernando de Azevedo e assinado por outros intelectuais em 1932. O programa de reforma proposto pelo referido documento argumentava que o Estado deveria adotar uma política global e nacional, abrangendo todos os níveis e modalidades de educação e ensino, enquanto que, na organização dos serviços e dos sistemas de educação e ensino, seria "[...] adotado o princípio da descentralização administrativa [...]” (Lemme, 2005, p. 172).

Em relação aos autores que assumem posições críticas, esses veem a municipalização apenas como um processo de desresponsabilização de uma instância central para uma periférica. Uma crítica forte presente em muitos estudos que analisam o processo de municipalização, que vem se instalando no Brasil, diz respeito à imposição constitucional para que os municípios assumam maiores responsabilidades com a garantia de políticas sociais, como oferta do Ensino Fundamental obrigatório sem combinar com uma reorganização tributária. Ou seja, o governo federal transferiu parcela significativa de responsabilidades à esfera municipal, enquanto se mantém no controle de maior parcela de recursos financeiros (descentralização da educação via municipalização).

Arelaro (2007) lembra que a Constituição Federal não produziu um projeto articulado de redistribuição de renda no país, mas, um processo de desconcentração de recursos, do governo central para estados e municípios, ao tempo que descentralizou novas responsabilidades sociais. Segundo a autora, cerca de $70 \%$ dos municípios brasileiros não possuem autonomia financeira para suas despesas regulares e, portanto, apresentam pouca condição de se viabilizarem como esferas públicas autônomas, principalmente porque esses municípios dependem, exclusivamente, de recursos originados do FPM (Fundo de Participação dos Municípios). Com esse modelo de municipalização, ampliam-se as desigualdades entre os municípios ricos e os mais pobres. Esses últimos, sem autonomia financeira, não encontram condições de cumprirem com suas novas responsabilidades, transformando-se, no máximo, em meros “[...] executores de programas nacionais e estaduais [...]" (Arelaro, 2007, p. 04).

Sabe-se que a discussão sobre municipalização do ensino no Brasil não é nova e desde a década de 1920 vem ocupando a atenção de educadores, políticos, administradores e especialistas em Educação. A

Educação \& Realidade, Porto Alegre, v. 38, n. 4, p. 1283-1301, out./dez. 2013.1285

Disponível em: <http://www.ufrgs.br/edu_realidade> 
A Movimentação das Matrículas no Ensino Fundamental no Estado do Piauí

proposta discutida, à época, tinha inspiração no modelo educacional norte-americano, o qual era fortemente descentralizado (Militão, 2011). Na década de 1970, a municipalização passou a ser amparada na legislação, com a instituição da Lei 5.692/71, Art.58, parágrafo único,

Art. 58. A legislação estadual supletiva, observado o disposto no artigo 15 da Constituição Federal, estabelecerá as responsabilidades do próprio Estado e dos seus Municípios no desenvolvimento dos diferentes graus de ensino e disporá sobre medidas que visem a tornar mais eficiente a aplicação dos recursos públicos destinados à educação. Parágrafo único. As providências de que trata este artigo visarão à progressiva passagem para a responsabilidade municipal de encargo e serviços de educação, especialmente de $1^{\circ}$ grau, que pela sua natureza possam ser realizados mais satisfatoriamente pelas administrações locais.

A Lei 5.692/71 orientava os municípios para assumirem as primeiras etapas da Educação Básica, apontando para a municipalização do ensino. Tal orientação continuou na Constituição Federal de 1988, conforme estabelece o Art. 211, $\S 1^{\circ}$ e $2^{\circ}$,

Art. 211. A União, os Estados, o Distrito Federal e os Municípios organizarão em regime de colaboração seus sistemas de ensino.

$\$ 1^{\circ}$ - A União organizará e financiará o sistema federal de ensino e o dos Territórios, e prestará assistência técnica e financeira aos Estados, ao Distrito Federal e aos Municípios para o desenvolvimento de seus sistemas de ensino e o atendimento prioritário à escolaridade obrigatória.

$\S 2^{\circ}$ - Os Municípios atuarão prioritariamente no ensino fundamental e pré-escolar.

Como se observa na Lei 5.692/71, o Ensino Fundamental (então, ensino de $1^{\circ}$ grau) passava a ser de responsabilidade dos municípios e, com a Constituição Federal de 1988, essa responsabilidade se estendeu à Educação Infantil (ensino pré-escolar). Segundo Souza e Faria (2004, p. 926), o contexto da constituinte de 1988

[...] foi marcado por fortes reações ao centralismo do regime autoritário e por uma grande revalorização da instância local, e apesar da pluralidade de interesses, definiu-se a tendência de atribuição de uma maior autonomia aos Municípios, confirmada, no campo da educação, alguns anos após, pela nova Lei de Diretrizes e Bases da Educação (LDB) - Lei no 9.394 -, em 1996.

Guimarães e Pinto (2001), estudando a evolução da participação da rede municipal de ensino fundamental nas matrículas da rede pública por região (1987 a 1999), mostram a mudança no perfil da distribuição de responsabilidades entre estado e municípios no atendimento do Ensino Fundamental, a partir de 1996. Segundo esses autores, a muni-

1286 Educação \& Realidade, Porto Alegre, v. 38, n. 4, p. 1283-1301, out./dez. 2013. Disponível em: <http://www.ufrgs.br/edu_realidade> 
cipalização avançou tanto na Região Nordeste, onde os municípios já tinham assumido mais da metade da rede pública de Ensino Fundamental, quanto no Sudeste, onde esta participação, em 1996, era de apenas um quarto do total. Os referidos autores chamam atenção para o fato de ser exatamente nas regiões mais pobres do País onde mais avançou a responsabilização dos municípios pelo Ensino Fundamental e onde os recursos disponíveis por aluno atingem patamares claramente insuficientes, especialmente após 1998, quando ocorreu a instituição do FUNDEF em todo o País.

Segundo Bassi e Fermino (2011), a instituição do FUNDEF criou mecanismo de indução que estimulou os municípios a ampliarem seu atendimento no Ensino Fundamental, com vistas a obter mais receitas ou para, pelos menos, recuperar a parcela automaticamente retida pelo FUNDEF O efeito do FUNDEF, nos seus primeiros anos de vigência, teve impacto, em nível nacional, na municipalização do Ensino Fundamental, movimento observado com a transferência de matrículas da esfera estadual para a municipal e com a expressiva expansão da oferta, possivelmente pela inclusão de crianças fora da escola.

Ainda segundo Bassi e Fermino (2011, p. 05-06),

[...] a redistribuição dos recursos financeiros promovida pelo FUNDEF atenuou as grandes disparidades de gasto por aluno do ensino fundamental existente entre a rede estadual e as redes municipais no âmbito de cada Estado. Ocorreu imediata e substancial transferência de recursos financeiros dos governos estaduais aos municipais, na maioria dos estados da Região Nordeste, onde o ensino fundamental se encontrava municipalizado desde a década de 1970. O oposto ocorreu em estados das Regiões Sul e Sudeste, onde a matrícula se concentrava na rede estadual. No início, os municípios transferiram recursos financeiros aos estados. Mas, em poucos anos, o intenso processo de municipalização induzido pelo FUNDEF reverteu essa direção, tornando alguns governos estaduais transferidores de receita aos municípios.

As afirmações de Bassi e Fermino (2011) reforçam os achados de Guimarães e Pinto (2001), os quais apresentaram resultados sobre a municipalização do Ensino Fundamental que ocorreu em todas as Regiões do Brasil. As afirmações desses dois autores reafirmam a necessidade de se analisar a movimentação das matrículas do ensino fundamental no Estado do Piauí, com vistas a preencher uma lacuna e conhecer a especificidade do fenômeno da municipalização no Estado do Piauí.

Dentro dos limites deste trabalho, por falta de espaço, não se entrará no mérito das vantagens e desvantagens da municipalização. Sendo assim, para efeitos de análise, neste trabalho, a municipalização toma como foco o processo de transferência de matrículas das redes estadual para a municipal no âmbito do Estado do Piauí como estratégia

Educação \& Realidade, Porto Alegre, v. 38, n. 4, p. 1283-1301, out./dez. 2013.1287 Disponível em: <http://www.ufrgs.br/edu_realidade> 
A Movimentação das Matrículas no Ensino Fundamental no Estado do Piauí

para acelerar o processo de descentralização do ensino a partir da implantação do FUNDEF em 1996.

A literatura que discute o processo de municipalização do ensino, pela via da transferência de matrícula de uma determinada esfera administrativa ou rede de ensino para outra em todo o país (federal, estadual e municipal), apresenta ainda, além de resultados por Regiões do Brasil, estudos de casos por estado.

Callegari (2011) analisa o processo de municipalização no Estado de São Paulo e evidencia que, num período extremamente curto (1996 a 2003), a presença do Governo do Estado na oferta de ensino de $1^{\mathrm{a}}$ a $4^{\mathrm{a}}$ séries caiu de $86 \%$ para $44 \%$, com centenas de prefeituras passando a operar nessa faixa de ensino. Naquele estado, o fenômeno teve início ainda no final de 1995, três anos antes do início do FUNDEF, quando o Governo do Estado de São Paulo passou a implementar várias ações com vistas a facilitar a transferência, de parte de sua rede de escolas, para os municípios. Nesse sentido, as escolas de Ensino Fundamental foram reorganizadas, criando-se milhares de unidades especializadas nos anos iniciais do Ensino Fundamental; e outras, separadamente, passaram a oferecer apenas o ensino nos anos finais do Ensino Fundamental, eventualmente junto com o ensino de nível médio. Com menor complexidade e mais próximas à estrutura funcional das chamadas pré-escolas, mantidas pelas prefeituras, as escolas estaduais dos anos iniciais do Ensino Fundamental se tornaram o alvo prioritário do processo de municipalização (Callegari, 2011).

\section{O Financiamento da Educação Básica a partir de 1998}

A partir da Constituição Federal de 1988 (CF/88), estados, municípios e o Distrito Federal deveriam aplicar, em Educação, no mínimo $25 \%$ da receita resultante de impostos, compreendida a proveniente de transferências, na manutenção e desenvolvimento do ensino. A CF/88 delegou aos municípios atuação prioritária na educação infantil e no ensino fundamental; aos estados e Distrito Federal delegou a atuação prioritária no ensino fundamental e ensino médio. O texto constitucional, mesmo definindo prioridades no atendimento da Educação Básica para estados e municípios, não conseguiu evitar atendimento fora das áreas prioritárias por esses entes federados. Com a instituição da Lei de Diretrizes e Bases da Educação Nacional (LDB), em 1996, as determinações constitucionais são reafirmadas: o atendimento prioritário dos municípios na Educação Infantil e Ensino Fundamental, e, aos estados, estes devem assegurar o Ensino Fundamental e oferecer, prioritariamente, o Ensino Médio a todos que o demandarem.

Com a instituição do FUNDEF (de 1998 até 2007), o nível de ensino privilegiado passou a ser o Ensino Fundamental, pois os $25 \%$ destinados à educação deveriam ser assim aplicados: 15\% no Ensino Fundamental e $10 \%$ nas demais etapas e modalidades da Educação Básica e no En-

1288 Educação \& Realidade, Porto Alegre, v. 38, n. 4, p. 1283-1301, out./dez. 2013 Disponível em: <http://www.ufrgs.br/edu_realidade> 
sino Superior. O foco do FUNDEF no Ensino Fundamental provocou o crescimento das matrículas dessa etapa do ensino, as quais atingiram, em poucos anos, a quase universalização desse nível de ensino (98\%). No entanto, o FUNDEF, ao subvincular recursos apenas para o Ensino Fundamental, desestimulou o atendimento da Educação Infantil, do Ensino Médio e da Educação de Jovens e Adultos. Os gestores das redes estaduais, para não perderem recursos, terminaram negligenciando o atendimento do Ensino Médio (sua área prioritária), e voltaram suas atenções para o Ensino Fundamental, passando a concorrer com as redes municipais nas matrículas para o Ensino Fundamental.

Depois da LDB de 1996, houve uma movimentação natural de matrículas da educação infantil dos estados para os municípios, e as matrículas dos municípios que atendiam o ensino médio foram transferidas para as redes estaduais. O Ensino Fundamental, embora sendo uma prioridade para o atendimento dos municípios, deve ser assegurado pelos estados, portanto, essa etapa do ensino pode ser oferecida tanto pelas redes municipais quanto pelas redes estaduais. Portanto, no caso da Educação Infantil e do Ensino Médio, não houve necessidade de as redes estaduais e municipais disputarem esses atendimentos. Em alguns estados, essa disputa ocorreu em busca dos alunos do Ensino Fundamental, havendo uma tendência de os municípios se destacarem no atendimento dos anos iniciais e os estados de se destacarem no atendimento dos anos finais dessa etapa do ensino. Essa disputa ganhou um elemento novo com a publicação da lógica do FUNDEF, a qual estimulou uma corrida em busca de se ampliar o atendimento no Ensino Fundamental. Por essa lógica, cada aluno contabilizado no Censo Escolar do ano anterior era revertido em receita, no ano seguinte. Nesse caso, qualquer aumento na quantidade de alunos, já em 1997, representaria aumento nas receitas de estados e municípios em 1998.

Portanto, em 1996, já estava desenhado o novo cenário do financiamento da educação pública no Brasil, dando início ao fenômeno das transferências de matrículas, das redes estaduais para as municipais, que ficou conhecido como municipalização do ensino.

Para se compreender melhor como se deu a dinâmica da movimentação das matrículas das redes estadual e municipal no Estado do Piauí, é preciso, antes, que seja apresentada a lógica de financiamento instituída pelo FUNDEF/FUNDEB, apresentando-se, em seguida, discussão sobre o fenômeno da municipalização no Brasil.

\section{A Lógica do FUNDEF/FUNDEB}

No mesmo ano em que entra em vigor a LDB/96, foi aprovada a Emenda Constitucional no14, que criava o FUNDEF, e a Lei 9.424, que o regulamentava. Embora o FUNDEF tenha entrado em vigor, em todo o País, apenas em janeiro de 1998, seu impacto nas matrículas já poderia ser sentido, mesmo antes de sua instituição, uma vez que toda a legis-

Educação \& Realidade, Porto Alegre, v. 38, n. 4, p. 1283-1301, out./dez. 2013.1289 Disponível em: <http://www.ufrgs.br/edu_realidade> 
A Movimentação das Matrículas no Ensino Fundamental no Estado do Piauí

lação do FUNDEF já havia sido publicada. Portanto, as novas regras do financiamento da educação pública já eram do conhecimento de todos, especialmente do conhecimento dos estados e dos municípios.

Após a vigência do FUNDEF, a lógica do financiamento das escolas públicas da educação básica mudou no Brasil. A partir de então, foi criado, no âmbito de cada estado, um fundo de natureza contábil, que arrecadava 15\% de alguns impostos e transferências (FPM e FPE). A arrecadação do FUNDEF era rateada entre as redes de ensino (estadual e municipal), de forma proporcional à quantidade de alunos matriculados no ano anterior. Portanto, quanto maior a quantidade de matrícula, maior seria o volume de recursos repassados a uma rede de ensino. Em função dessa lógica de proporcionalidade de matrículas, estabeleceuse, no Piauí, uma disputa por aluno do Ensino Fundamental. Neste sentido, cada rede de ensino procurava ampliar seu atendimento. Conforme foi dito anteriormente, as redes de ensino, a fim de receber um repasse maior de recursos do FUNDEF, recorriam a campanhas publicitárias, no início de cada ano, com vistas a atrair mais alunos. Várias estratégias eram feitas pelas redes estaduais e municipais para ampliar suas matrículas, uma vez que, no contexto de um mesmo município geralmente havia escolas municipais e estaduais realizando o mesmo atendimento. Assim, dependendo do contexto de cada estado, as matrículas do Ensino Fundamental passaram a ser objeto de disputa entre estado e município.

Ainda sobre as receitas do FUNDEF, o Tesouro Nacional realizava cálculos para determinar o valor per capita no âmbito de cada estado. Para tanto, dividia o total arrecadado no estado (a soma das contribuições para o FUNDEF do estado e de seus municípios) pelo total de alunos matriculados no Ensino Fundamental, no ano anterior. Nos estados em que o valor per capita encontrado fosse menor que o valor-aluno fixado anualmente pela União, esta deveria repassar recursos (complementação) para o fundo daquele estado até igualar o valor per capita pelo valor-aluno/ano fixado pela União.

Durante o FUNDEF e agora com o FUNDEB, o Estado do Piauí sempre teve que receber complementação da União. Por possuir pequena atividade econômica, arrecadava (e continua arrecadando) um volume pequeno de impostos, consequentemente contribuía muito pouco para o FUNDEF e vem contribuindo, ainda, muito pouco para o FUNDEB.

O que mudou na passagem do FUNDEF para o FUNDEB a partir de 2007? Segundo Bassi e Fermino (2011, p. 11),

[...] o FUNDEB preservou os mecanismos de captura e de redistribuição de recursos instaurados pelo FUNDEF. Estendeu, porém, significativamente a abrangência de financiamento a todas as etapas e modalidades da educação básica, contando, para isso, com um maior aporte de

1290 Educação \& Realidade, Porto Alegre, v. 38, n. 4, p. 1283-1301, out./dez. 2013. Disponível em: <http://www.ufrgs.br/edu_realidade> 
recursos decorrente da elevação do percentual subvinculado de um número maior de impostos (Brasil, 2007). Implantado também em âmbito estadual, os novos fundos processam operações contábeis que recolhem a maior parte da receita gerada pela vinculação que os Estados, o DF e os Municípios têm de destinar às despesas com MDE e, depois, as redistribui aos governos, proporcionalmente de acordo com o número de matrículas de Educação Básica, obedecendo às competências estabelecidas no artigo 211 da CF/88.

Tanto no FUNDEF quanto no FUNDEB, o Governo Federal passou a fixar anualmente um valor mínimo nacional por aluno (valor-aluno/ ano), com vista a atender os estados em que seus valores per capita não atingissem o referido valor mínimo nacional, atendimento esse que ficou conhecido como complementação da União.

Até o ano de 1999, o valor-aluno/ano fixado pelo Governo Federal era o mesmo para todos os níveis do Ensino Fundamental. De 2000 até 2004, o valor aluno/ano passa a considerar um valor para os anos iniciais do Ensino Fundamental e outro valor (5\% maior) para os anos finais do Ensino Fundamental, recompensando mais os entes federados que mais atendiam os referidos anos finais. De 2005 a 2006, o valoraluno/ano começa a considerar a localidade da escola (zona urbana e zona rural), passando a apresentar quatros valores: anos iniciais urbanos, anos iniciais rurais, anos finais urbanos e anos finais rurais, agora, recompensando mais pelos alunos da zona rural, pois o valor-aluno/ ano passou a ser $20 \%$ maior, em relação aos alunos da zona urbana. A partir de 2007, foi instituído o FUNDEB e desde então toda a Educação Básica passou a ser contemplada com recursos do fundo. O valor-aluno/ ano passou a contemplar mais etapas e modalidades do referido nível de ensino, criando, assim, fatores de ponderação entre as etapas e modalidades.

A etapa da Educação Básica usada como base para o cálculo são os anos iniciais do Ensino Fundamental urbano, com fator de ponderação 1,00 (um). As outras etapas e modalidades são menores ou maiores que 1,00 (um), conforme estabelecer, em cada ano, a Comissão Intergovernamental de Financiamento para a Educação Básica de Qualidade, que é composta por representantes dos municípios, estados e pelo Ministro da Educação.

Em 2010, os fatores de ponderação apresentaram variação entre 0,7 e 1,3. De 2008 para 2009, não houve reajustes significativos nos fatores. A modalidade que registrou maior crescimento no indicador foi a Educação de Jovens e Adultos integrada à educação profissional. O fator passou de 0,70 para 1,00 . Isso significa que em 2008 os valores repassados, anualmente, para os alunos da EJA equivaliam a $70 \%$ do custo do estudante das séries iniciais urbanas. Já em 2009, os alunos da EJA passaram a corresponder ao mesmo valor dos alunos dos anos iniciais

Educação \& Realidade, Porto Alegre, v. 38, n. 4, p. 1283-1301, out./dez. 2013.1291 Disponível em: <http://www.ufrgs.br/edu_realidade> 
A Movimentação das Matrículas no Ensino Fundamental no Estado do Piauí

do ensino fundamental urbano, ou seja, R\$1.221,34. Com o FUNDEB, a diferença entre o valor-aluno/ano dos anos iniciais e dos anos finais do Ensino Fundamental cresceu de $5 \%$ para $10 \%$, tornando as matrículas deste segmento ainda mais atrativas para os entes federados que mais atendiam os anos finais dessa etapa da Educação Básica.

\section{Movimentação das Matrículas no Estado do Piauí}

Para analisar a movimentação das matrículas no Estado do Piauí, foi preciso coletar dados sobre as matrículas, com vistas a montar uma série histórica, compreendendo informações do período de vigência do FUNDEF e início do FUNDEB. Neste artigo é analisada uma séria histórica, de 1997 até 2010, das matrículas, a partir de dados disponibilizados no site do INEP e de informações complementares nos microdados, a fim de desagregar informações não encontradas no referido site no período de 1997 a 1999.

Antes de apresentar os dados de matrículas, é importante analisar a evolução da quantidade de nascidos vivos no Estado do Piauí, com vistas a observar se existe alguma correlação entre o crescimento e a queda das matrículas com a quantidade de nascidos vivos no período considerado. É importante considerar que os nascidos vivos em um ano só entram no sistema escolar alguns anos depois, seja iniciando na Educação Infantil, seja no Ensino Fundamental.

TABELA 1 - Evolução da Quantidade de Nascidos Vivos no Piauí e Teresina (1997 - 2009)

\begin{tabular}{ccc}
\hline ANO & PIAUÍ & TERESINA \\
\hline $\mathbf{1 9 9 7}$ & 32.422 & 17.148 \\
$\mathbf{1 9 9 8}$ & 46.753 & 16.040 \\
$\mathbf{1 9 9 9}$ & 49.436 & 16.721 \\
$\mathbf{2 0 0 0}$ & 58.615 & 17.255 \\
$\mathbf{2 0 0 1}$ & 58.588 & 15.834 \\
$\mathbf{2 0 0 2}$ & 56.332 & 14.498 \\
$\mathbf{2 0 0 3}$ & 55.105 & 14.491 \\
$\mathbf{2 0 0 4}$ & 54.747 & 14.349 \\
$\mathbf{2 0 0 5}$ & 56.866 & 14.290 \\
$\mathbf{2 0 0 6}$ & 55.342 & 14.585 \\
$\mathbf{2 0 0 7}$ & 53.214 & 13.465 \\
$\mathbf{2 0 0 8}$ & 52.664 & 14.047 \\
$\mathbf{2 0 0 9}$ & 50.996 & 13.577 \\
\hline Fonte: Ministérioda Saúde/Datasus.
\end{tabular}

Fonte: Ministério da Saúde/Datasus.

1292 Educação \& Realidade, Porto Alegre, v. 38, n. 4, p. 1283-1301, out./dez. 2013. Disponível em: <http://www.ufrgs.br/edu_realidade> 


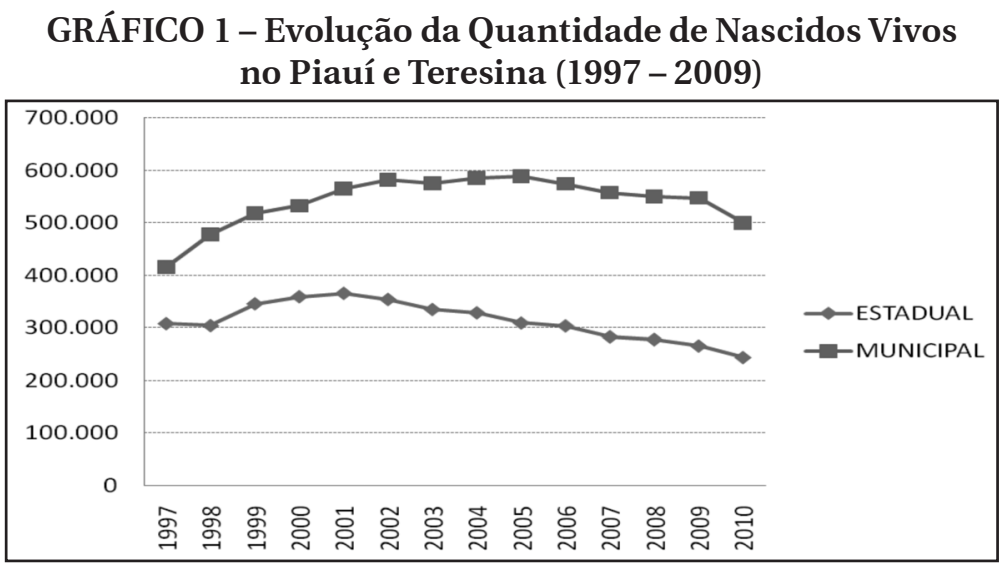

Fonte: Elaborado pelos autores a partir de dados do Ministério da Saúde/Datasus.

Pode-se observar, na Tabela 1 e Gráfico 1, que o Estado do Piauí apresentou crescimento na quantidade de nascidos vivos de 1997 a 2000. A partir desse ano, a quantidade de nascidos vivos começa a decrescer até 2009, ano no qual termina a série histórica. Observa-se que, em toda a série histórica, a capital do Piauí (Teresina) manteve uma tendência de queda na quantidade de nascidos vivos. Essa tendência de queda merece estudos posteriores que possam explicar suas razões.

Em seguida, são analisadas as matrículas da Educação Básica no Piauí, considerando-se dados da rede estadual e da rede municipal. Observando a Tabela 2 e Gráfico 2, pode-se constatar o crescimento das matrículas das duas redes, de 1997 a 2003 e a redução das matrículas de 2004 a 2010.

\section{TABELA 2 - Matrículas da Educação Básica no Piauí das Redes} Estadual e Municipal (1997-2010)

\begin{tabular}{l|r|r|r|r|r}
\hline \multicolumn{1}{c}{ ANO } & \multicolumn{1}{c}{ ESTADUAL } & \multicolumn{1}{c}{ MUNICIPAL } & \multicolumn{1}{r}{ MATRICULA } & \multicolumn{1}{c}{$\begin{array}{r}\text { ESTADUAL } \\
(\mathbf{\%})\end{array}$} & $\begin{array}{r}\text { MUNICIPAL } \\
(\mathbf{\%})\end{array}$ \\
\hline $\mathbf{1 9 9 7}$ & 307.947 & 415.606 & 723.553 & 42,6 & 57,4 \\
\hline $\mathbf{1 9 9 8}$ & 304.038 & 478.158 & 782.196 & 38,9 & 61,1 \\
\hline $\mathbf{1 9 9 9}$ & 345.853 & 517.628 & 863.481 & 40,1 & 59,9 \\
\hline $\mathbf{2 0 0 0}$ & 359.356 & 532.070 & 891.426 & 40,3 & 59,7 \\
\hline $\mathbf{2 0 0 1}$ & 365.910 & 564.136 & 930.046 & 39,3 & 60,7 \\
\hline $\mathbf{2 0 0 2}$ & 354.154 & 580.779 & 934.933 & 37,9 & 62,1 \\
\hline $\mathbf{2 0 0 3}$ & 335.020 & 574.981 & 910.001 & 36,8 & 63,2 \\
\hline $\mathbf{2 0 0 4}$ & 328.551 & 583.939 & 912.490 & 36,0 & 64,0 \\
\hline $\mathbf{2 0 0 5}$ & 309.088 & 588.079 & 897.167 & 34,5 & 65,5 \\
\hline $\mathbf{2 0 0 6}$ & 303.544 & 573.803 & 877.347 & 34,6 & 65,4 \\
\hline $\mathbf{2 0 0 7}$ & 283.026 & 556.790 & 839.816 & 33,7 & 66,3 \\
\hline $\mathbf{2 0 0 8}$ & 277.759 & 548.917 & 826.676 & 33,6 & 66,4 \\
\hline $\mathbf{2 0 0 9}$ & 265.732 & 546.870 & 812.602 & 32,7 & 67,3 \\
\hline $\mathbf{2 0 1 0}$ & 243.693 & 499.204 & 742.897 & 32,8 & 67,2 \\
\hline
\end{tabular}

Fonte: Inep. 


\section{GRÁFICO 2 - Matrículas da Educação Básica no Piauí das Redes Estadual e Municipal (1997 - 2010)}

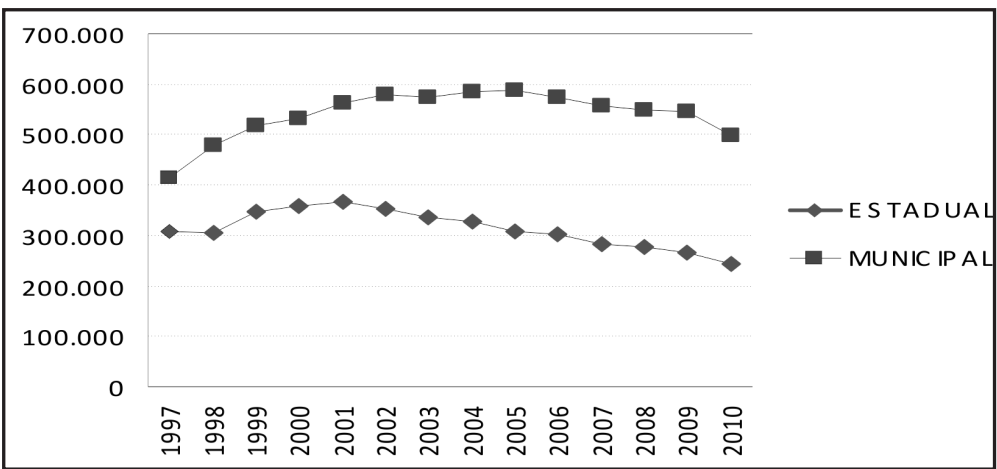

Fonte: Elaborado pelos autores a partir de dados do Inep.

O período de crescimento das duas redes de ensino (Estadual e Municipal), entre 1997 e 2002, sugere que não houve municipalização na Educação Básica, no período, embora se observe que houve um maior crescimento das matrículas municipais. Entre 2003 e 2010, embora havendo redução de matrícula nas duas redes de ensino, podese afirmar que houve municipalização, uma vez que o percentual de municipalização cresceu de $2003(62,2 \%)$ para 2010 (67,2\%). A perda de matrícula observada, a partir de 2003, se deve ao efeito demográfico, expresso pela diminuição da quantidade de nascidos vivos no Piauí. Outros fatores contribuíram para a redução das matrículas, entre eles está a redução da distorção idade/série dos alunos, provocada pela organização da escolaridade em ciclos, com vistas a reduzir a repetência e a evasão escolar. Têm contribuído também para a redução da distorção idade/série os programas de correção do fluxo escolar.

Segundo Bassi e Fermino (2011), no Brasil, outro fator que contribuiu para a redução das matrículas está relacionado com a mudança na metodologia utilizada pelo INEP, a partir de 2007, para realizar o Censo Escolar, o Educacenso, que, ao informatizar a coleta de informações educacionais, eliminou as matrículas duplicadas.

Portanto, na movimentação das matrículas da Educação Básica, de 1997 a 2010, observou-se um baixo percentual de municipalização no Piauí (de 60,0\% em 1997 a 66,5\% em 2010)

Em seguida, são analisadas as matrículas do Ensino Fundamental do Piauí, observando-se inicialmente a movimentação das matrículas nos anos iniciais do Ensino Fundamental, nas duas redes consideradas. 
TABELA 3 - Matrículas dos Anos Iniciais do Ensino Fundamental no Piauí das Redes Estadual e Municipal (1997 - 2010)

\begin{tabular}{c|c|c|c|c|c}
\hline ANO & ESTADUAL & MUNICIPAL & $\begin{array}{c}\text { MATRÍCULA } \\
\text { TOTAL }\end{array}$ & $\begin{array}{c}\text { ESTADUAL } \\
\mathbf{( \% )}\end{array}$ & $\begin{array}{c}\text { MUNICIPAL } \\
(\mathbf{\%})\end{array}$ \\
\hline $\mathbf{1 9 9 7}$ & 160.703 & 328.875 & 489.578 & 32,8 & 67,2 \\
\hline $\mathbf{1 9 9 8}$ & 146.982 & 376.670 & 523.652 & 28,1 & 71,9 \\
\hline $\mathbf{1 9 9 9}$ & 140.324 & 387.793 & 528.117 & 26,6 & 73,4 \\
\hline $\mathbf{2 0 0 0}$ & 130.820 & 376.163 & 506.983 & 25,8 & 74,2 \\
\hline $\mathbf{2 0 0 1}$ & 123.047 & 372.975 & 496.022 & 24,8 & 75,2 \\
\hline $\mathbf{2 0 0 2}$ & 106.259 & 359.056 & 465.315 & 22,8 & 77,2 \\
\hline $\mathbf{2 0 0 3}$ & 88.243 & 337.615 & 425.858 & 20,7 & 79,3 \\
\hline $\mathbf{2 0 0 4}$ & 83.319 & 326.900 & 410.219 & 20,3 & 79,7 \\
\hline $\mathbf{2 0 0 5}$ & 76.445 & 319.302 & 395.747 & 19,3 & 80,7 \\
\hline $\mathbf{2 0 0 6}$ & 70.884 & 308.594 & 379.039 & 18,6 & 81,4 \\
\hline $\mathbf{2 0 0 7}$ & 63.489 & 292.647 & 356.136 & 17,8 & 82,2 \\
\hline $\mathbf{2 0 0 8}$ & 60.159 & 284.072 & 344.231 & 17,5 & 82,5 \\
\hline $\mathbf{2 0 0 9}$ & 54.152 & 275.786 & 329.938 & 16,4 & 83,6 \\
\hline $\mathbf{2 0 1 0}$ & 44.685 & 261.614 & 306.299 & 14,6 & 85,4 \\
\hline & & \multicolumn{5}{|c}{ Fonte: Inep e Observatório da Educação. } &
\end{tabular}

GRÁFICO 3 - Matrículas dos Anos Iniciais do Ensino Fundamental no Piauí das Redes Estadual e Municipal (1997 - 2010)

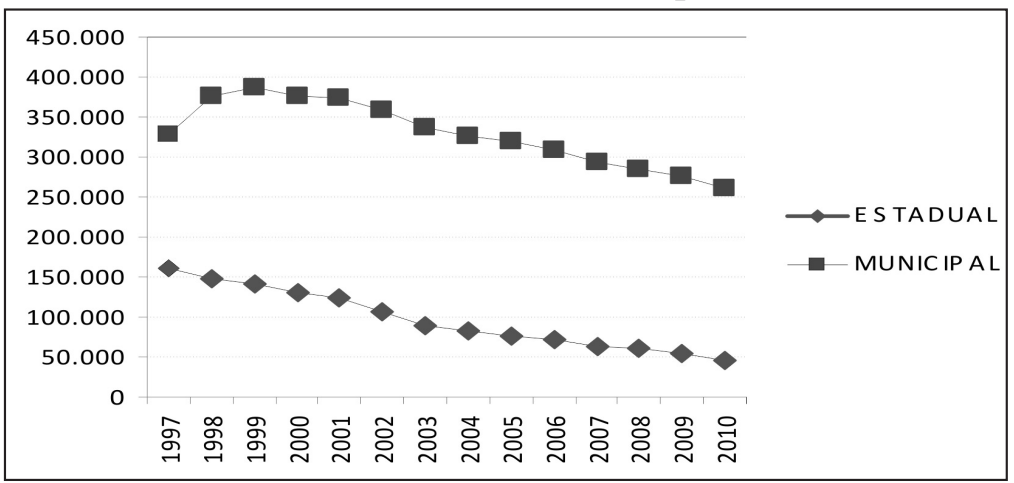

Fonte: Elaborado pelos autores a partir de dados do Inep e Observatório da Educação.

Na Tabela 3 e no Gráfico 3, pode ser observada a movimentação das matrículas dos anos iniciais do Ensino Fundamental no Piauí das redes Estadual e Municipal. Percebe-se que as matrículas da rede municipal cresceram fortemente de 1997 a 1999; ao contrário, a rede estadual apresentou, gradativamente, redução em suas matrículas. Assim sendo, pode-se afirmar que, no referido período, o crescimento das matrículas da rede municipal, antes mesmo da vigência do FUNDEF, pode ser en-

Educação \& Realidade, Porto Alegre, v. 38, n. 4, p. 1283-1301, out./dez. 2013.1295 Disponível em: <http://www.ufrgs.br/edu_realidade> 
A Movimentação das Matrículas no Ensino Fundamental no Estado do Piauí

tendido como uma corrida antecipada dos municípios, por matrícula, com vistas a aumentar suas receitas. Dito de outro modo, segundo Bassi e Fermino (2011, p. 16), “[...] as redes municipais se anteciparam no incremento de matrículas de modo a se precaverem quanto aos impactos sobre suas receitas".

Nesse contexto, pode-se afirmar que, no Piauí, semelhante ao que aconteceu na maioria dos estados brasileiros, houve municipalização nos anos iniciais do Ensino Fundamental, período de 1997 a 2010. Essa afirmação fica evidenciada na Tabela 3, uma vez que o percentual de municipalização que, em 1997, era de 67,2\% subiu para 85,4\% em 2010. No período de 1999 a 2010, observa-se uma tendência de perda constante de matrículas nas redes estadual e municipal, fato claramente evidenciado pelo quase perfeito paralelismo das duas curvas, as quais apresentam inclinações semelhantes no referido período. O declínio das matrículas do Ensino Fundamental, no Estado do Piauí, não pode ser explicado pelo efeito demográfico (ver análise da Tabela 1 e Gráfico 1), porque, no Gráfico dos nascidos vivos no Piauí, o ponto máximo da curva é o ano 2000, ou seja, um ano depois do início da queda das matrículas nos anos iniciais do Ensino Fundamental. Sem considerar que os nascidos vivos em um ano só entram no sistema escolar alguns anos depois, seja iniciando na Educação Infantil, seja no Ensino Fundamental.

Também não se pode considerar o efeito dos programas de correção de fluxo escolar, já que o primeiro município a utilizar esses programas (Teresina) iniciou suas atividades em 2002; seu impacto só seria perceptível a posteriori. Muito menos pode se considerar significativo o efeito da mudança de metodologia utilizada pelo INEP, pois o seu impacto foi a partir de 2007, ano de sua implantação. Assim sendo, resta uma explicação plausível, a qual pode estar associada ao recuo ${ }^{6}$ de alguns municípios em maquiar os dados do censo escolar, os quais provavelmente foram inflacionados de 1997 a 1999, a partir da divulgação das regras do FUNDEF.

Finalmente, são analisadas as matrículas dos anos finais do Ensino Fundamental do Piauí, observando-se a movimentação ocorrida nas matrículas das duas redes consideradas.

Pode ser observada, pela Tabela 4 e pelo Gráfico 4 , a movimentação das matrículas dos anos finais do Ensino Fundamental no Piauí, da rede Estadual e Municipal. A movimentação observada destaca os períodos: de 1997 a 2001 (crescimento das matrículas das duas redes), de 2002 a 2005 (crescimento da rede municipal e redução da rede estadual) e de 2006 a 2010 (redução das matrículas nas duas redes).

1296 Educação \& Realidade, Porto Alegre, v. 38, n. 4, p. 1283-1301, out./dez. 2013 Disponível em: <http://www.ufrgs.br/edu_realidade> 
TABELA 4 - Matrículas dos Anos Finais do Ensino Fundamental no Piauí das Redes Estadual e Municipal (1997 - 2010)

\begin{tabular}{l|r|r|r|r|r}
\hline ANO & ESTADUAL & MUNICIPAL & \multicolumn{1}{c}{$\begin{array}{c}\text { MATRÍCULA } \\
\text { TOTAL }\end{array}$} & $\begin{array}{c}\text { ESTADUAL } \\
\mathbf{( \% )}\end{array}$ & $\begin{array}{c}\text { MUNICIPAL } \\
(\mathbf{\%})\end{array}$ \\
\hline $\mathbf{1 9 9 7}$ & 80.014 & 32.611 & 112.625 & 71,0 & 29,0 \\
\hline $\mathbf{1 9 9 8}$ & 87.602 & 48.926 & 136.528 & 64,2 & 35,8 \\
\hline $\mathbf{1 9 9 9}$ & 123.935 & 67.927 & 191.862 & 64,6 & 35,4 \\
\hline $\mathbf{2 0 0 0}$ & 125.223 & 91.008 & 216.231 & 57,9 & 42,1 \\
\hline $\mathbf{2 0 0 1}$ & 132.097 & 116.950 & 249.047 & 53,0 & 47,0 \\
\hline $\mathbf{2 0 0 2}$ & 118.103 & 146.903 & 265.006 & 44,6 & 55,4 \\
\hline $\mathbf{2 0 0 3}$ & 89.730 & 163.764 & 253.494 & 35,4 & 64,6 \\
\hline $\mathbf{2 0 0 4}$ & 80.574 & 172.002 & 252.576 & 31,9 & 68,1 \\
\hline $\mathbf{2 0 0 5}$ & 69.590 & 173.085 & 242.675 & 28,7 & 71,3 \\
\hline $\mathbf{2 0 0 6}$ & 67.441 & 165.481 & 232.922 & 29,0 & 71,0 \\
\hline $\mathbf{2 0 0 7}$ & 61.473 & 156.148 & 217.621 & 28,2 & 71,8 \\
\hline $\mathbf{2 0 0 8}$ & 61.859 & 153.458 & 215.317 & 28,7 & 71,3 \\
\hline $\mathbf{2 0 0 9}$ & 62.332 & 156.146 & 218.478 & 28,5 & 71,5 \\
\hline $\mathbf{2 0 1 0}$ & 61.196 & 151.680 & 212.876 & 28,7 & 71,3 \\
\hline & & & & &
\end{tabular}

GRÁFICO 4 - Matrículas dos Anos Finais do Ensino Fundamental no Piauí das Redes Estadual e Municipal (1997 - 2010)

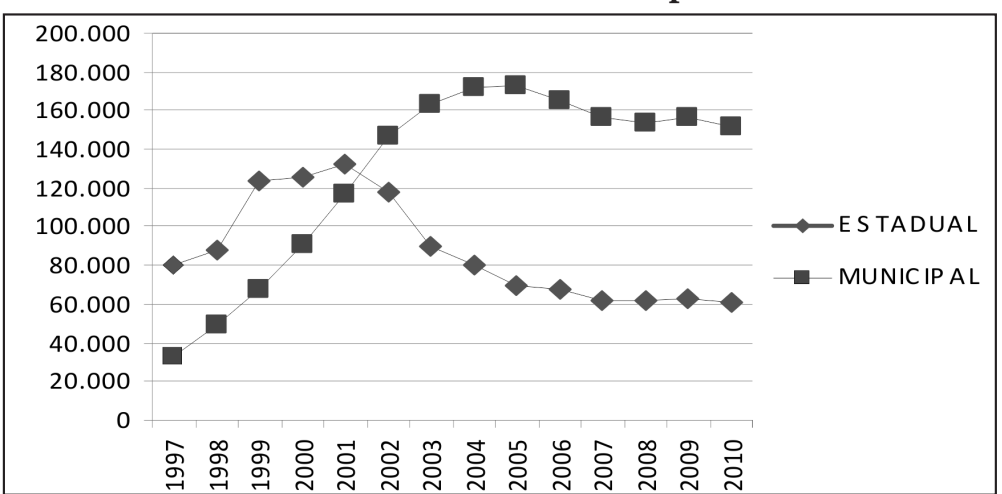

Fonte: Elaborado pelos autores a partir de dados do Inep e Observatório da Educação.

De 1997 a 2001, observa-se o crescimento simultâneo das matrículas das redes Estadual e Municipal. No período de 1997 a 2001, embora possa se observar o crescimento das duas redes de ensino, observa-se uma maior participação das redes municipais no total das matrículas nessa etapa do Ensino Fundamental no Estado, configurando-se, assim, o início da municipalização no Piauí, também nas matrículas dos anos finais do Ensino Fundamental nesse período (1997 a 2001), a muni-

Educação \& Realidade, Porto Alegre, v. 38, n. 4, p. 1283-1301, out./dez. 2013.1297 Disponível em: <http://www.ufrgs.br/edu_realidade> 
A Movimentação das Matrículas no Ensino Fundamental no Estado do Piauí

cipalização subiu de 29,0\% para 47,0\%, contrariando a tendência, apontada por Callegari (2011), de as redes municipais se especializarem nos anos iniciais e as redes estaduais se especializarem nos anos finais do Ensino Fundamental.

De 2002 a 2005, evidencia-se o crescimento da rede municipal e a redução da rede estadual, ou seja, crescimento e redução na mesma proporção, configurando forte municipalização no referido período (a municipalização subiu de 55,4\% para 71,3\% de 2002 a 2005). De 2005 a 2010, o percentual de municipalização estabilizou-se na faixa de $71 \%$. A municipalização dos anos finais do ensino fundamental, da mesma forma, ocorreu de forma diferente do fenômeno ocorrido em São Paulo, que foi observado por Callegari (2011).

De 2006 a 2010, pode-se afirmar que houve estabilidade no processo de municipalização, uma vez que as redes estadual e municipal, igualmente, apresentaram perdas constantes de matrículas, tendência evidenciada pelo quase perfeito paralelismo das duas curvas, as quais apresentam inclinações semelhantes no referido período (2006 a 2010). Nesse período, pode-se observar uma menor perda de matrículas, com certa estabilidade, a partir de 2007, acompanhando a tendência da curva dos nascidos vivos no Piauí.

\section{Conclusão}

Este artigo teve como objetivo analisar as matrículas do Ensino Fundamental, no Estado do Piauí, das redes estadual e municipais, no período entre 1996 e 2010. No recorte temporal, levou-se em consideração o período de vigência do FUNDEF e os primeiros anos de vigência do FUNDEB, a partir de 2007, fundos que alteraram a lógica de financiamento da educação nos Estados, Municípios e no Distrito Federal; portanto, trouxeram novos elementos para a oferta do Ensino Fundamental, etapa da Educação Básica analisada.

A análise, aqui realizada, tomou como referência os estudos de Callegari (2011), Arelaro (2007), Pinto e Guimarães (2001) e Bassi e Fermino (2011). Esses autores reconhecem que o processo de municipalização teve início bem antes da instituição do FUNDEF, no entanto, afirmam que foi somente a partir dele que a municipalização ganhou um ritmo mais acelerado, não obtido com a legislação anterior. Neste sentido, Militão (2011) e Souza e Faria (2004) afirmam que outros fatores, relacionados à legislação, também contribuíram para o referido processo de municipalização, tais como a Lei 5.692/71, a CF/88 e LDB/96.

Ao se analisar a movimentação das matrículas dos anos iniciais do ensino fundamental no Piauí, observou-se que, semelhante ao que ocorreu na maioria dos estados brasileiros, de 1997 a 2010, ocorreu municipalização nessa etapa de ensino.

Tal afirmação é evidenciada na análise da Tabela 3 e do Gráfico 3, uma vez que o percentual de municipalização que, em 1997, era de

1298 Educação \& Realidade, Porto Alegre, v. 38, n. 4, p. 1283-1301, out./dez. 2013 Disponível em: <http://www.ufrgs.br/edu_realidade> 
$67,2 \%$ subiu para 85,4\% em 2010. Observou-se que, no período de 1999 a 2010, houve uma tendência constante de perda de matrículas nas redes estadual e municipal, claramente visível, pelo paralelismo das duas curvas, as quais apresentam inclinações semelhantes no referido período (1999 a 2010). Observou-se ainda que o crescimento das matrículas da rede municipal, antes mesmo da entrada em vigor do FUNDEF, pode ser entendido como uma corrida antecipada dos municípios, por matrícula, com vistas a aumentar suas receitas.

Em relação às matrículas dos anos finais do ensino fundamental, foram observados movimentos distintos em três períodos na série histórica analisada. De 1997 a 2001, observou-se o crescimento simultâneo das matrículas das redes estadual e municipal, evidenciando-se a municipalização no referido período, pois houve maior participação da rede municipal no total das matrículas realizadas nessa etapa do ensino no estado.

De 2002 a 2005, constatou-se uma evidência plausível de municipalização nos anos finais do Ensino Fundamental no Piauí, ao se constatar o crescimento e redução, na mesma proporção, das matrículas da rede municipal e a da rede estadual, respectivamente. A municipalização dos anos finais do Ensino Fundamental, no Piauí, ocorreu de forma diferente do fenômeno ocorrido em São Paulo, o qual foi destacado por Callegari (2011), na introdução deste trabalho, que apontou forte municipalização apenas nos anos iniciais do ensino fundamental.

O último período analisado dos anos finais do Ensino Fundamental (2006 a 2010) contemplou 1 ano do FUNDEF e 4 anos do FUNDEB. Nesse período, constatou-se que houve estabilidade no processo de municipalização, uma vez que as redes estadual e municipal, igualmente, apresentaram perdas constantes de matrículas, observando-se certa estabilidade a partir de 2007, acompanhando a tendência da curva dos nascidos vivos no Piauí.

A partir dos resultados apresentados, ficou evidenciado que o processo de municipalização das matrículas do Ensino Fundamental, no Piauí, teve características peculiares. Tal processo não ocorreu somente nos anos iniciais do Ensino Fundamental, como era de se esperar, mas veio a configurar-se, fortemente, nos anos finais do Ensino Fundamental. As razões das peculiaridades da municipalização das matrículas do Ensino Fundamental no Piauí e os contextos econômicos e políticos, por não terem sido objeto deste artigo, ficarão como objeto de futuras pesquisas.

Recebido em 10 de maio de 2012 Aprovado em 22 de agosto de 2012

\section{Notas}

$1 \mathrm{O}$ texto foi produzido no contexto da pesquisa nacional "Remuneração de professores de escolas públicas da educação básica: configurações, impactos, impasses e perspectivas", financiada segundo o Edital no. 001/2008 da CAPES

Educação \& Realidade, Porto Alegre, v. 38, n. 4, p. 1283-1301, out./dez. 2013. 1299 Disponível em: <http://www.ufrgs.br/edu_realidade> 
A Movimentação das Matrículas no Ensino Fundamental no Estado do Piauí

/ INEP / SECAD - Observatório da Educação, realizada junto ao Centro de Estudos e Pesquisas em Políticas Públicas de Educação (CEPPPE) da Faculdade de Educação da Universidade de São Paulo, coordenada nacionalmente pelo Prof. Dr. Rubens Barbosa de Camargo, sendo desenvolvida em 12 Estados (São Paulo, Paraná, Rio Grande do Sul, Santa Catarina, Mato Grosso do Sul, Mato Grosso, Paraíba, Piauí, Roraima, Pará, Minas Gerais e Rio Grande do Norte), envolvendo 09 programas de Pós-Graduação em Educação (USP, UFPA, UFPI, UFPB, UFRN, UEMG, UFMS, UFPR, UNISUL), contando ainda com 04 grupos colaboradores de pesquisa (USP-RP, UNIFESP, UFMT, UFRGS).

$2 \mathrm{O}$ termo rede municipal será utilizado neste artigo para referir-se a todas as redes municipais do Estado.

3 Fundo de Manutenção e Desenvolvimento do Ensino Fundamental e de Valorização do Magistério.

4 Fundo de Manutenção e Desenvolvimento da Educação Básica e de Valorização dos Profissionais da Educação.

5 Os dados foram complementados a partir dos microdados do INEP, pois no site do INEP as informações de 1997 a 1999 não estavam desagregadas, em nível de anos iniciais e finais do Ensino Fundamental.

60 recuo pode estar associado ao surgimento das primeiras denúncias de fraudes no Censo Escolar, cometidas por alguns municípios.

\section{Referências}

ARELARO, Lisete Regina Gomes. FUNDEF: uma avaliação preliminar dos dez anos de sua implantação. (GT: Estado e Política Educacional; n. 05, 2007). Disponível em: <http://www.anped.org.br/reunioes/30ra/trabalhos/GT05-3866-Int.pdf $>$. Acesso em: 18 jul. 2012.

BASSI, Marcos Edgar. FERMINO, Phelipe Pires. O Atendimento à Educação Básica em Santa Catarina: repercussões do FUNDEF e do FUNDEB na matrícula pública. 2011. Disponível em: <http://nupefe.blogspot.com/2010/09/o-atendimento-educacao-basica-em-santa.html>. Acesso em: 20 jul. 2011.

BRASIL. Constituição (1988). Constituição da República Federativa do Brasil. Brasília, DF: Senado Federal, 1988. Disponível em: < http://www.planalto.gov. br/ccivil_03/Constituicao/Constituicao.htm >. Acesso em: 20 jul. 2011.

BRASIL. Emenda Constitucional no 14, de 12/09/1996. Modifica os artigos. 34, 208, 211 e 212 da Constituição Federal e dá nova redação ao art. 60 do Ato das Disposições constitucionais Transitórias. 1996a. Disponível em: <http://www. planalto.gov.br/ccivil_03/Constituicao/Emendas/Emc/emc14.htm>. Acesso em: 20 jul. 2011.

BRASIL. Emenda Constitucional nº 53, de 19/12/2006. Dá nova redação aos artigos. $7^{\circ}, 23,30,206,208,211$ e 212 da Constituição Federal e ao art. 60 do Ato das Disposições Constitucionais Transitórias. 2006b. Disponível em: <http://www. planalto.gov.br/ccivil_03/Constituicao/Emendas/Emc/emc53.htm>. Acesso em: 20 jul. 2011.

BRASIL. Lei no. 5.692, de 11/08/1971, Fixa Diretrizes e Bases para o ensino de $1^{\circ} \mathrm{e}$ $2^{\circ}$ graus, e dá outras providências. 1971. Disponível em: <http://www.planalto. gov.br/ccivil_03/Leis/L5692.htm>. Acesso em: 20 jul. 2011.

BRASIL. Lei no 9.394, de 20/12/1996. Estabelece as diretrizes e bases da educação nacional. 1996b. Disponível em: <http://www.planalto.gov.br/ccivil_03/ Leis/L9394.htm>. Acesso em: 20 jul.2011.

BRASIL. Lei no 9.424, de 24/12/1996. Dispõe sobre o Fundo de Manutenção e Desenvolvimento do Ensino Fundamental e de Valorização do Magistério. 1996c.

1300 Educação \& Realidade, Porto Alegre, v. 38, n. 4, p. 1283-1301, out./dez. 2013 Disponível em: <http://www.ufrgs.br/edu_realidade> 
Disponível em: <http://www.planalto.gov.br/ccivil_03/Leis/L9424.htm>. Acesso em: 20 jul. 2011.

BRASIL. Lei no 11.494, de 20/06/2007. Regulamenta o Fundo de Manutenção e Desenvolvimento da Educação Básica e de Valorização dos Profissionais da Educação - FUNDEB. 2007. Disponível em: <http://www.planalto.gov.br/ccivil_03/_Ato2007-2010/2007/Lei/L11494.htm>. Acesso em: 20 jul. 2011.

BRASIL. Medida Provisória n⿳3 339, de 28/12/2006. Regulamenta o art. 60 do Ato das Disposições Constitucionais Transitórias e dá outras providências. 2006b. Disponível em: <http://www.planalto.gov.br/ccivil_03/_Ato2004-2006/2006/ Mpv/339.htm>. Acesso em: 20 jul. 2011.

BRASIL. Ministério da Educação e Cultura. INEP. Microdados. Disponível em: <http://portal.inep.gov.br/basica-levantamentos-microdados>. Acesso em: 20 jul. 2011.

BRASIL. Ministério da Saúde. Datasus. Disponível em: <http://www2.datasus. gov.br/DATASUS/index.php>. Acesso em: 20 jul. 2011.

CALLEGARI, César. Uma Nova Supervisão para um Novo Mapa Educacional Paulista. Disponível em: <http://www.cesarcallegari.com.br/artigos/Download/nova\%20sup\%20um\%20novo\%20mapa\%20educ.doc $>$. Acesso em: 20 jul. 2011.

GUIMARÃES, José Luiz; PINTO, José Marcelino Rezende. A Demanda pela Educação Infantil e os Recursos Disponíveis para seu Financiamento. Em Aberto, Brasília, v. 18, n. 74, p. 92-105, dez. 2001.

LEMME, Paschoal. O Manifesto dos Pioneiros da Educação Nova e suas Repercussões na Realidade Educacional Brasileira. Revista Brasileira de Estudos Pedagógicos, Brasília, p. 172, v. 86, n. 212, p. 1-233, jan./abr. 2005.

MILITÃO, Silvio César Nunes. Municipalização do Ensino Fundamental em São Paulo: o FUNDEF como divisor de águas. 2010. Disponível em $<\mathrm{http}$ ://forum.ulbratorres.com.br/2010/mesa_texto/MESA\%206\%20C.pdf>. Acesso em: 20 jul. 2011.

SOUZA, Donaldo Bello de; FARIA, L. C. Macedo de. Reforma do Estado, Descentralização e Municipalização do Ensino no Brasil: a gestão política dos sistemas públicos de ensino pós-LDB 9.394/96. Ensaio: Avaliação e Políticas Públicas em Educação, Rio de Janeiro, v. 12, n. 45, p. 925-944, out./dez. 2004.

Luís Carlos Sales é doutor em Educação pela Universidade Federal do Piauí (UFPI, 1995). Mestre em Educação pela Universidade Federal do Rio Grande do Norte (UFRN, 1999). Professor Associado da Universidade Federal do Piauí em Teresina, no estado do Piauí. É Parecerista ad hoc do INEP, CNPq e CAPES. E-mail:lwis2009@yahoo.com.br

Magna Jovita Gomes de Sales e Silva é mestra em Educação (UFPI, 2008) e Doutoranda do Programa de Pós-Graduação em Educação da Universidade Federal do Piauí. Atualmente é Professora da Educação Básica da Rede Pública de Ensino Estadual e Municipal de Teresina em Teresina, no estado do Piauí. E-mail: magnajgss@hotmail.com 